\title{
Entrepreneurship through Agriculture in Nigeria
}

\author{
Clement C. M. Ajekwe ${ }^{1} \&$ Adzor Ibiamke ${ }^{2}$ \\ ${ }^{1}$ Department of Accounting, Benue State University, Makurdi, Nigeria \\ 2 Department of Accounting and Management, Nigerian Defence Academy, Kaduna \\ Correspondence: Adzor Ibiamke, Department of Accounting, Nigerian Defence Academy, Kaduna, Nigeria. Tel: \\ 234-706-555-3623. E-mail: aibiamke@nda.edu.ng
}

Received: January 17, 2020

Accepted: February 29, 2020

Online Published: March 20, 2020

doi:10.5430/bmr.v9n1p35

URL: https://doi.org/10.5430/bmr.v9n1p35

\begin{abstract}
Poverty is one of the supreme challenges in Nigeria. This paper explores entrepreneurship in agriculture as a strategy for a drastic reduction in unemployment and poverty in Nigeria. Agriculture creates employment opportunities to $70 \%$ $-75 \%$ of the Nigerian working population and contributes about $20.9 \%$ of Nigeria's total gross domestic product. Yet, young educated and ambitious Nigerians do not show much interest in agriculture. Currently, Nigerian farmers are elderly, toiling away with outdated techniques and tools. Not only are these old farmers unlikely to use latest technologies that guarantee rewards in agriculture and afford a modern lifestyle. The youth believe that career in agriculture would "condemn" them to a "backwards", "dirty" lifestyle associated with the elderly "uneducated" farmers currently performing physical arduous backbreaking farm work. Meanwhile, the educated and ambitious youth struggle almost hopelessly to find employment in the few highly esteemed sectors, such as the civil service, banking, engineering, medicine and law. This paper persuades youths to take up a career in the agricultural sector through entrepreneurship activities; the paper tells stories of successful educated young entrepreneurs in agriculture. Some young successful educated and ambitious agri-preneurs are identified and their stories are told. These agri-preneurs are potential role models (i.e., people whose achievements in agricultural entrepreneurship the youths can emulate/imitate). The paper advises youths to start small with simple straightforward projects capable of producing cash rewards in the short-term and to look out for the several government and $\mathrm{UN}$ grants opportunities that encourage agropreneurship. Before launching their enterprises, aspiring agri-preneurs are counselled to avail themselves of training and apprentice opportunities from successful agri-preneurs.
\end{abstract}

Keywords: agriculture, agri-preneur, entrepreneurship, farming, success stories, Nigeria

\section{Introduction}

For a very long time, revenues accrued from oil and gas resources have contributed to the retardation of agricultural development in Nigeria. However, with the current fall in the price of crude oil in the international markets, a Nigerian economy underpinned by oil and gas resources is no longer desirable. The consequences of falling oil prices in the international market is devastating; companies are downsizing and cutting salaries, people are losing their jobs, businesses are failing, employment opportunities are drying up, young people have difficulties finding paid employment/jobs. As a consequence of these developments, the country is moving towards other revenue streams of which agriculture (and the food sector in particular) is uniquely positioned to provide new revenue streams to Nigerians. Agriculture is uniquely positioned in the Nigerian economy. Agriculture provides food and nutrition to a population estimated at $190-200$ million and creates employment opportunities through forward and backward linkages to support $70 \%-75 \%$ of the Nigerian working population. This implies that agriculture and the economy are synonymous; one cannot modernise the economy without starting with agriculture (Juma, 2011). That is not all; about $20.9 \%$ of Nigeria's total GDP was contributed by agriculture in the first quarter of 2016 (National Bureau of Statistics). Furthermore, Nigeria is endowed with factors that support agricultural development; these agricultural development drivers include a large population (190 - 200 million) and an increasing urbanised middle class with "good" disposable income, among others. These economic fundamentals are strong, as the level of political support for food security is high. The macro-economic policy of the Federal Government of Nigeria is hinged on agriculture being the pillar of the policy framework and drive for diversification from oil and gas. These facilitative factors provide opportunities to Nigerians in agriculture. 
That is not all. Nigeria is endowed with over 82 million square kilometres of lands which are cultivatable, of these, less than $10 \%$ is under permanent cultivation (NBS, 2015). Yet, food in large quantities is imported into Nigeria; this apparent illogical behaviour is heightened when it is obvious that large plots of fertile land are lying fallow and uncultivated. This situation presents a paradox which can be explained by the fact that young people do not show much interest in farming. For now, in Nigeria, agricultural activities are often done by the elderly (50+) with limited formal education. Not only are these old farmers unlikely to generate adequate productivity to afford a modern lifestyle, the youth belief that a career in agriculture would similarly "condemn" them to a life that can be characterised as "backwards" and "dirty"; a lifestyle associated with the "uneducated" elderly farmers currently performing physical arduous backbreaking farm work. Meanwhile, these educated and ambitious youth struggle almost hopelessly to find employment in the few highly esteemed sectors, such as the civil service, banking, engineering, medicine and law. In the absence of educated entrepreneurs in agriculture, who would act as "role models", young people wishing to take a career in agriculture are confronted by challenges regarding how to enter the field or access the resources to make them successful. Messages from the government, agricultural colleges, and agricultural departments in the universities suggest that agriculture is a technical vocation, rather than an entrepreneurial pursuit imbued with creativity, innovation, profitability and many other positive manifestations that would stimulate educated and ambitious youth of the 21 st century.

This paper emphasises a pressing need to engage the youth in ways that they can see a promising career in the agricultural value chain. Moreover, the requirements of agriculture, i.e., innovation and physical strength make agriculture ideally suited for young people who may be graduates of secondary and tertiary institutions. Nigerian youths are well endowed in energy/strength, creativity, innovation and entrepreneurship; these are some of the characteristics needed for agriculture that delivers food security and preserves the fragile natural environment.

The paper is structured as follows: section 2 reviews literature covering the concept of agricultural entrepreneurship, theoretical underpinning of the paper and opportunities in agricultural entrepreneurship. Section 3 speaks to the methodology adopted by the paper, followed by stories of successful young educated and ambitious entrepreneurs are told in section 4 . The concluding comments are contained in section 5.

\section{Literature Review}

\subsection{Concept of Entrepreneurship and Agricultural Entrepreneurship}

Entrepreneurship has several associative concepts: having an "entrepreneurial mind", an "entrepreneurial spirit", "being passionate about one's undertaking", "seeing one's enterprise as a business", "taking financial risks in the hope of making profit", "bringing about beneficial innovations and creative transformations", "increasing productivity"; "creating employment for self and others", "making improvements to one's standard of living in an economy", "eradicating poverty through legal and socially acceptable means", among others. Agricultural entrepreneurship results when the associative concepts and ideas of entrepreneurship are applied in agriculture. Therefore, those who undertake business activities within the agricultural value chain with an entrepreneurial spirit are agricultural entrepreneurs- agri-preneurs. Agri-preneurs will initiate and accelerate transformative agricultural changes that raise productivity to a level of reducing real food prices, yet boosting rural incomes and creating jobs, and making financial profit from performing the activity or activities in any stage(s) of the agricultural value chain.

\subsection{Theoretical Foundation}

This paper is underpinned by conversion and social influence theories. Conversion theory suggests that a few successful agri-preneurs can have a positive disproportionate effect in converting the "majority's" preference for paid employment in the few highly esteemed sectors to a self-employment career in agriculture. Conversion theory is particularly applicable where the preference of the "majority" arises from a false belief that there is no other alternative, in this case, to paid employment. Social influence theory is all about behavioural change that one person causes to another deliberately or unintentionally as a result of the way the "transformed" persons perceive themselves in a new light. In the context of this paper, it is expected that educated youths, seeing that other equally educated youths are entrepreneurs in agriculture, would themselves be influenced to compliance by planning a career in agri-preneurship especially where employment opportunities in the preferred sectors are scarce.

\subsection{Opportunities in the Agricultural Value Chain}

There are enormous amount of opportunities in agriculture, agricultural platforms, including agricultural markets that young entrepreneurs can tap into. Some of these are discussed below: 


\subsubsection{Agricultural Value Chain}

For the purpose of this paper, agriculture consists of producers of agricultural inputs, farmers, dealers in agricultural produce, processors of agricultural produce, manufacturers of agricultural machinery and implements and agricultural distributors and distribution (including exports). Input producers and dealers make the practice of agriculture possible. Input producers and dealers sell to farmers, improved seeds, technology, fertilisers, herbicides, pesticides, etc. They also sell implements, tools and agricultural machinery used on the farms.

Farmers are producers of grain and forage crops. Farmers plant, grow, maintain, harvest and sell produce such as yams, rice, cassava, maize, beans, as well as vegetables and other specialty crops such as flowers and plants that are used for landscaping purposes. A farmer may also choose to specialize in various areas of agriculture such as horticulture, aquaculture, poultry, fruit and vegetable production, livestock production, animal husbandry and many other areas.

Dealers in agricultural produce buy and sell agricultural products; they store and/ or transport agricultural produce under the right conditions for subsequent distribution to wholesalers, retailers or the final consumer. Agricultural processors process agricultural produce for human and/or animal consumption as well as for industrial use. For example, cassava is processed to garri, flour, animal feeds, starch, among others; palm fruits are processed into palm oil, palm kernel oil, animal feeds etc. Agricultural manufacturers design and manufacture farm equipment such as dryers, pruning machines, harvesters, trimmers, hydraulic components etc. Agricultural distributors and exporters focus on logistics: stocking farm produce and distributing to wholesalers, retailers or consumers nationwide or for export.

\subsubsection{Agricultural Inputs}

For agriculture to prosper, farm inputs need to be available, affordable, accessible, and of good quality. Seeds, fertilizers, and agrochemicals, are essential for improving the productivity and incomes of farmers in developing countries (World Bank, 2007, 2013; Rosegrant, Paisner, Meijer \& Witcover, 2001; AGRA, 2013; FAO, 2013). In Nigeria, reduction in poverty can be achieved by enhancing the productivity and, and by extension, profitability of agriculture through productivity- enhancing investments in agricultural inputs, such as fertilizers, improved seeds and water control measures (FAO, 2010). This assertion is anchored on the strong positive relationship that exists between fertilizer application and crop yields (Liverpool-Tasie, Olaniyan, Salau \& Sckey, 2010). Empirically, it has been established that one kilogram of nitrogen delivered through fertilizer increases crop yields by 7-10kg on average (Jayne, Rashid, Minot \& Kasule, 2009). However, fertilizer use in Nigeria is low and estimated at $13 \mathrm{~kg} / \mathrm{ha}$ (FMARD, 2010) compared to the $200 \mathrm{~kg}$ /ha recommended by the United Nations Food and Agriculture Organization (FAO). No wonder, Banful, Nkoya and Oboh (2010) identified low fertiliser use as a major challenge that must be overcome in order to increase Nigeria's agricultural productivity. On their part, Nagy and Edun (2002) blame inadequate use of fertilizer in Nigeria on non-availability and high cost of credit. Following the Abuja Declaration (2006) in which African agricultural leadership resolved to up-scale input dealerships and community-based networks across rural areas as a means to achieving the region's green revolution objectives; African countries believed that by this action, farmers' access to fertilisers would improve. In addition, the Federal Government of Nigeria (FGN) decided to disengage from direct procurement of fertiliser in favour of promoting private sector participation. Disengagement by the FGN from direct procurement of fertilisers creates opportunities for private sector engagement in fertiliser distribution. Youths drawn to the idea of making a profit helping people working with the soil will enjoy starting and operating a fertiliser distribution business after drawing up a business plan.

The Food and Agriculture Organization (FAO) emphasises using improved seeds as necessary for a rapid increase in crop production and productivity. Improved seeds/stock have been described as the fulcrum of modern agriculture (FAO, 2015) and one of the most economical and efficient inputs to agricultural development (Neate \& Guei, 2010).

Success of agricultural revolution in China and south-East Asia is attributed to improved seed varieties (Trippe, 1995; Joshua, 1999; Louwaars \& Marrewijk, 1999). In Nigeria, the IITA/FAO has identified the challenges confronting Nigerian farmers to include the use of seeds of low quality (mostly on-farm saved grain as opposed to purchased certified seeds) and the significantly low rates of fertilizer use.

Youths may wish to launch and build a market-driven seed business to produce and distribute improved seeds after drawing up a business plan, Other agricultural input businesses in which Nigerian youths can express their entrepreneurship includes distribution and marketing of herbicides, pesticides, knapsacks, etc. Youths may also wish to seek a career in providing Information and Communication Technology (ICT) services of benefit to agri-preneurs; this involves using innovative ways in providing agricultural information. Deployment of ICTs has the potential to enhance efficiency, by providing on-line much needed information, such as pre-harvest and post-harvest information, pricing, 
weather conditions etc. ICT tools, such as mobile phones and the networks needed to connect them are now available everywhere providing new avenues and offering critical information to farmers on production systems management, market access services and financial inclusion (FAO, 2013; Meera, Jhamtani, \& Rao, 2004).

\subsubsection{Farming}

In terms of both variety and scale of operations, farming is possibly the most heterogeneous of activities on the agricultural value chain. It consists of growing crops (arable farming), keeping animals (pastoral farming) or growing crops and raising animals simultaneously (mixed farming) for food and raw materials. Arable farming includes crop farming (rice, cassava yams, beans, maize, groundnuts, etc), vegetable farming (cucumber, carrot, bitter leaf, onion, tomatoes etc). Pastoral farming includes keeping animals (goat, sheep, cows, pigs, and rabbits), poultry and fish farming. In terms of scale, farming ranges from growing crops in the backyard or keeping goats and bees, fish, etc., in the backyard to large scale farming on several hectares of land. Farming opportunities abound in Nigeria for graduates of tertiary institutions irrespective of their discipline of study. More than 85 million square kilometres of Nigeria is arable land, of which only about $10 \%-40 \%$ is cultivated implying a huge potential for engagement by the youth.

\subsubsection{Dealing in Agricultural Produce}

Certain factors make dealing in agricultural produce profitable. Food is a basic demand of all households all the year round. Yet, not only is crop production seasonal, many ecological zones are unsuited for production of all crops. These facts create opportunities for dealing in agricultural produce in terms of transportation from supply-based areas to areas of high demand with or without the necessity of storage and preservation from the "on- season" to the "off-season". Agricultural entrepreneurs can engage in the foodstuff storage and distribution business locally, nationally as well as internationally. Foodstuffs can be bought from the local market for distribution to adjoining urban centre eateries and other consumers. At the national level, foodstuffs can be purchased in bulk from one part of the country for resale in other parts where such commodity is required. For example, palm oil can be purchased from the south-south region for sale in the north central region while oranges can be bought from the north- central for sale in the north-west regions. Agricultural entrepreneurs can also be agents of agricultural produce exporters procuring products like ginger, cashew nuts, sesame seeds, spices, etc from farmers or agricultural dealers for exports by the export agents.

\subsubsection{Agricultural Processing}

Agricultural processing consists of primary, secondary and tertiary processing of agricultural products For our purpose, agricultural processing refers to tertiary processing of common Nigerian crops (cereals and legumes, tuber and root crops, fruits and vegetables) and livestock, fish and other food items and cash crops at the commercial level for profit. Particular crop processing opportunities include; processing cassava into garri, fufu, flour, starch, animal feeds, chips and pellets, processing of rice, oil palm, yams, fruits and vegetables, oil bearing seeds such as ground nuts and soybeans into oils, cakes and animal feeds. Other opportunities include processing meat (beef, goat, mutton and pork), poultry, fish and snails.

\subsubsection{Manufacturing and leasing agricultural equipment}

Current farming technology in Nigeria involves a lot of drudgery. To overcome the drudgery, farmers need to utilise agricultural machinery; tractors, processing and packaging machinery. This need creates an opportunity for agricultural entrepreneurs to manufacture/procure, supply or lease agricultural equipment to farmers in Nigeria. Other agricultural equipment are planting equipment, fertiliser applicators, and tools or implements for weeding and harvesting crops, sprayers, seeding equipment etc. Agricultural equipment is relatively expensive to purchase especially for the youth. In the circumstances, the youth can seek opportunities in being leasing brokers linking farmers and leasing companies.

\section{Methodology}

In this paper we use the "call to action" storytelling technique to drive action, to persuade and to influence Nigerian youths to take to entrepreneurship in agriculture. Story telling is known to greatly increase the chances of moving listeners to action (David, 2015). Factual have ability to grasp patterns of living within a very personal, emotional experience (McKee, 1997). Therefore, in this paper we relay success stories of other youths in order to make the authors' persuasive communication relatable and trustworthy.

\section{Stories of Young Nigerian Agricultural Entrepreneurs}

Stories of selected young (18-35) Nigerian agri-preneurs are presented to provide ideas for entrepreneurship in agriculture and to stimulate the interest of other young people in the profession of agriculture. 


\subsection{Cynthia Mosunmola Umoru}

Cynthia Mosunmola Umoru is an agro-entrepreneur doing business as Honeysuckles PTL Ventures, a farming outfit that also markets freshly processed chickens, snails and catfish to mainly quick service restaurants in Nigeria. Cynthia is a Zoology/Animal Biology graduate of the University of Lagos. Her journey has not been all smooth. During the first five years of her outing, she experienced financial drawbacks. Today, the story is different; she is very successful. As a result, she is determined to show young people that farming can be glamorous and good fortune for them. Cynthia speaks before secondary school students and undergraduates wearing the most glamorous attire associated more with the higher echelons of urban society, declaring "I am a farmer" proudly, intriguing the audience as farmers are usually not associated with such an opulent appearance. Her appearance and the fluency and poignancy with which she delivers her speeches converts the audience into farming enthusiasts who then sign-in to the farmers' clubs, she sets up, to participate in mini-livestock farming and vegetable gardening. Cynthia then takes students to her farm and combines them with a broader group of aspiring young agribusiness entrepreneurs, who have approached her for advice on different aspects of their budding agribusiness. Those with their own agribusinesses learn modern skills and ideas to incorporate into their endeavour, while the secondary school and university students begin to realize that farming does not have to look like their antiquated ideas. Cynthia has leveraged her initial publicity to engage schools and government to shift their thinking

\subsection{Clifford Eborgu}

Clifford Eborgu is the Chief Executive of Sendulus Consulting in Oyo State. Eborgu is leading a campaign to get young entrepreneurs involved in plantain farming for income and food. For him, plantain farming has ace in agro-business; the market is assured with high returns with low risk factors. A challenge for starters and young entrepreneurs in plantain farming is getting good suckers because of the high costs of the higher grades. For a farmer cultivating plantain on a large scale, this could be pretty expensive, just as it has been a challenge accessing high-yielding and disease-resistant plantlets. Many a farmer still relies on old low-producing suckers. Eborgu has access to an innovative propagation method which provides an affordable, simple and relatively rapid technique for multiplication of plantain for small and medium scale farmers. This macro propagation technique has the potential to overcome challenges faced by farmers, such as unavailability of affordable high yielding, quick maturing seedlings at the farm level. It assures affordable, qualitative suckers capable of allowing a single sucker to have up to $8-15$ new suckers. After propagation, it takes at most three weeks to see the plantlets shoot from the sucker and three months to have the suckers ready for planting. Through Eborgu's effort and others, small scale plantain production is now on the increase and the initiative has been so successful such that there is now a possibility of plantain surplus.

\subsection{Zanau Hassan Maikasuwa}

After graduating with B. Agriculture (Crop Production) from the University of Maiduguri in 2008, Zanau Hassan Maikasuwa started Farm-fields Agro-Allied Services, a for-profit social enterprise in Taraba State. The aim of this enterprise is to scale up smallholder farmers to commercial farming by providing agricultural extension services, including sales of improved quality seeds and other inputs to farmers, training of farmers on innovative farming practices that lead to increased yields and income, carrying out field demonstration trials at various farming communities, providing undergraduate internship training for students of university faculties of agriculture, mentoring graduates in agri-business under the Graduate Internship Scheme of the Federal Government SURE-P, offering business development and consultancy services to start-up agri-preneurs, carrying out soil testing services and supplying soil test kits to agricultural professionals and farm survey services using GPS to determine farm size and advice farmers on input requirement. Farm-fields AgroAllied Services also farms crops and livestock on several hectares of land. Zanau is also involved in training women farmers to improve their farming skills that would result in increased yield and income that would enable them take care of their families. He also works and mentors youths to start and grow their business including developing winning business plans that enable them access business start-up grants.

\subsection{Sola Adeniyi}

After graduating in business administration, Sola Adeniyi made haste to fill a gap identified in the market for moringa by setting up Natural Nutrient Limited that deals in moringa. He first tested- marketed the product by supplying a small number of processed products and the result looked astonishing to him. He grew the business producing, packaging and distributing moringa in commercial quantities, baffled at the level of sales he made. He went a step further by manufacturing moringa tea and today the moringa tea has become greatly sought after especially among the health conscious population. His business has grown and expanded into moringa body butter, capsule, oil, soap and powder. He has also established a plantain estate in Ogun state to help busy Nigerians, who need a joint venture arrangement to 
run their agro-businesses while keeping their day jobs. To help those considering investing in moringa production, Adeniyi organises training and demonstration sessions and assisting them with disease- free plantlets to start their farms.

\subsection{Fatima Oyiza Ademoh}

Fatima Ademoh holds bachelor and master degrees from the American University of Nigeria and the University of Leeds UK respectively. Fatima is the founder of Ajima Youth Empowerment Foundation with several years' experience in business development, entrepreneurship, agribusiness, and more recently, she is promoting access to energy services for rural off-grid communities and agribusinesses. Fatima is a University lecturer of finance and mentor to Tony Elumelu Entrepreneurship Programme (TEEP) finalists during their entrepreneurial training.

Fatima has founded a training program known as Youth Agricbiz training, a social enterprise incubator that aims to create the next generation of Agricultural Entrepreneurs in Nigeria. The training is basically a theoretical and practical 18 months programme where youth are trained in agriculture and entrepreneurship and business planning and get paid while they learn. The pay during their program comes from the money they make off their agricultural practicals on The Ajuma Farm; a family-owned farm in Abuja. The payment is saved and given to the students at the end of their training to serve as seed money to start- off their agro business.

\subsection{Tochukwu Ikpegbu}

Tochukwu Ikpegbu, a mechanical engineering graduate is the CEO, Emmanuel Farms. After failing to secure paid employment, Tochukwu made enquiries regarding pork meat supply consequent upon being "thrilled" by a dose of spiced barbecued pork meat at a local eatery. Tochukwu was astonished to discover that large quantities of pork sold in most parts of his locality came from a far: North Central Nigeria. Tochukwu saw this as a huge business opportunity. In 2006, Tochukwu converted a room in his father's village compound in Umuahia Abia State into a pig farm starting off with twenty piglets. Today, Emmanuel Farms has expanded to four big pens housing over five hundred pigs; producing at least 100 piglets every month. The Farm supplies Prime Pork locally and nationwide through Wal- Mart and Shoprite Stores. In 2010, Ikpegbu came first in the Harambe Nigeria Agri-business Competition, winning up to 77.5 million in prizes and training with the Fate Foundation and Idea- Builders.

\section{Conclusion}

The case studies discussed are a living testimony that young educated people can become successful entrepreneurs in agriculture. These cases are intended to persuade and to influence Nigerian youths to take to entrepreneurship in agriculture. However, it is appreciated that two problems confront youths contemplating a career as agri-preneurs: What type of agricultural business to start? How to raise capital to start an agricultural business? To realistically capitalise on an initial interest and enthusiasm for agriculture, potential entrepreneurs are urged to start small with simple and straightforward projects capable of producing cash rewards in the short-term. Buying, storing and distributing agricultural produce, mini-livestock farming (e.g., raising snails, rabbits, etc.) and vegetable gardening are good examples of agricultural businesses to start with; these businesses take up little space and/or require little capital but can yield significant revenue quickly. Regarding raising initial capital, there are several government and UN grants opportunities open to youth to access. Indeed, it is said that the issue about raising capital is lack of awareness about where and how to raise it. Furthermore, aspiring agri-preneurs will do well to explore training and apprentice opportunities offered by some of the profiled successful agri-preneurs before launching their ventures. Thereafter, they would be in a confident position to raise capital for their agricultural businesses. It should be noted that the profiled agri-preneurs did not always succeed without problems; they had challenges. For example, Cynthia experienced initial financial drawbacks during the first five years of her outing. Tochukwu failed to secure paid employment as a graduate mechanical engineer and had to find an entrepreneurial inspiration from a "beer parlour". The going is not always easy, but as the saying goes "When the going gets tough, the tough get going".

\section{References}

AGRA, (2013). Africa agriculture status report 2013: Focus on staple crops. Alliance for a Green Revolution in Africa (AGRA), Nairobi, Kenya. http://www.agra.org/our-results/agra-status-reports/.

Banful, A. B., Nkonya, E., \& Oboh, V. (2010). Constraints to fertilizer use in Nigeria: Insights from agricultural extension service (IFPRI Discussion paper 01010). Abuja: Development Strategy and Governance Division, International Food Policy Research Institute. Retrieved from www.academia.edu/7978610/Constraints_to_fertilizer_use 
David, T. (2015). Why the Gettysburg address is still a great case study in persuasion; Harvard Business Review. Retrieved from https://hbr.org/2015/04/why-the-gettysburg-address-is-still-a-great-case-study-in-persuasion

FAO (2010). Agricultural input business development in Africa: Opportunities, issues and challenges. Report presented by ECA-SA during the working lunch on Public-Private Partnerships in Agribusiness and agro-industry development in Africa through regional Value Commodity chains held in Abuja on 9 March 2010. Retrieved from http://repository.uneca.org/bitstream/handle/10855/4379/BBib.\%2031540_I.pdf?sequence=1

FAO. (2013a). Guidelines for input trade fairs and voucher schemes. Food and Agriculture Organization of the United Nations (FAO), Rome, Italy. Retrieved from http://www.fao.org/docrep/018/aq418e/aq418e.pdf

FAO. (2013b). ICT uses for inclusive agricultural value chains. Rome. Retrieved from http://www.fao.org/docrep/017/aq078e/aq078e.pdf

FAO. (2015). Comments by the FAO country representative in Nigeria, Dr. Louise Setshwaelo at the TCP/NIR/3403 Project Strengthening National Seed System in Nigeria in Jos, Plateau State on 28 May 2015. https://agronigeria.com.ng/quality-seed-crucial-tool-for-food-security-fao/

Federal Ministry of Agriculture and Rural Development. (FMARD, 2010). Blueprint on Agriculture and Rural Development, A Presentation to the National Economic Management Team by the Honourable Minister of Agriculture and Rural Development, Abuja, Nigeria.

Jayne, T., Rashid, S., Minot, N., \& Kasule, S. (2009). Promoting fertilizer use in Africa: current issues and empirical evidence from the COMESA region. Presentation at the COMESA Africa Agricultural Markets Programme Policy Conference (June 15-16, 2009). Livingstone, Zambia

Joshua, A. (1999). The Emerging Private Seed Industries in Nigeria and the way forward in the millennium. Sustainable Maize Production in Nigeria. Proceedings of the National Maize Production Workshop, July 22 - 24, $A B U$, Zaria, SG 2000/IAR/FMARD/ADPs. pp. 108 - 121.

Juma, C. (2011). The New Harvest: Agricultural Innovation in Africa. New York: Oxford University Press.

Louwaars, M. P., \& Marrewijk, G. A. (1999). Seed Supply Systems in Developing Countries. CTA.

Kahan, D. (2013). Entrepreneurship in Farming. Rome: Food and Agriculture Organization of the United Nations.

Kaplinsky, R., \& Morris. (2000). A Handbook for Value Chain Research.

Katz, J., \& Green, R. (2013). Entrepreneurial Small Business (4th ed.). McGraw Hill/Irwin

Liverpool-Tasie, S., Olaniyan, B., Salau, S., \& Sackey, J. (2010). A Review of Fertiliser Issues in Nigeria. Nigeria Strategy Support Program (NSSP). NSSP Working Paper 0019.

Man, T., Lau, T., \& Chan, K. (2002). The competitiveness of small and medium enterprises: A conceptualisation with focus on entrepreneurial competencies. Journal of Business Venturing, 17(2), 123-142. https://doi.org/10.1016/S0883-9026(00)00058-6

McClelland, D., Mansfield, R., Spencer, L. (jnr), \& Santiago, J. (1987). The identification and assessment of competencies and other personal characteristics of enterprises in developing countries. Washington DC: USAID:

McKee, R. (1997). Story: Substance, Structure, Style, and the Principles of Screenwriting. Harper-Collins.

Meera, S., Jhamtani, A., \& Rao, D. (2004). Information and Communication Technology in Agricultural development: A comparative analysis of three projects from India. Retrieved from https://www.odi.org/sites/odi.org.uk/files/odi-assets/publications-opinion-files/5186.pdf

National Bureau of Statistics. (2015). Nigeria FAO Statistics: Land Use and Agricultural Inputs Retrieved from $\mathrm{http} / / /$ nso.nigeria.opendataforafrica.org/unrwvq/nigeria-fao-stat-land-use-and-agricultural-inputs

Nagy, J., \& Edun, O. (2002). Assessment of Nigerian Government Fertilizer

Neate P. J., \& Guei, R. G. (2010). Promoting the Growth and Development of Smallholder Seed Enterprises for Food Security Crops. Food and Agriculture Organization of the United Nations (FAO), Rome. Retrieved from http://www.fao.org/docrep/013/i1839e/i1839e00.pdf

Rosegrant, M. W., Paisner, M. S., Meijer, S., \& Witcover, J. (2001). Global food projections to 2020: emerging trends and alternative futures. International Food Policy Research Institute (IFPRI), Washington, DC, USA. http://www.ifpri.org/publication/global-food-projections-2020. 
The Abuja 2006 Fertilizer Summit Declaration and Resolutions.

Tripp, R. (1995). Seed Regulatory Frameworks and Resource Poor Farmers: A literature Review, Network Paper 51. Agricultural Administration Research and Extension, ODI, London.

World Bank, (2007). World Development Report 2008: Agriculture for Development. Washington, DC, USA.

World Bank, (2013). Unlocking Africa's Agricultural Potential. Washington, DC, USA. 